\title{
Inhibitive effect of Thymus satureioides essential oil as a green corrosion inhibitor for mild steel in an acidic medium
}

\section{A. Boukhraz, ${ }^{1}$ A. Chaouik, ${ }^{2,3}$ R. Salghi, ${ }^{3}$ H. Elhartiti, ${ }^{1}$ N. Saouide el ayne, ${ }^{4}$ A. Zaher ${ }^{1}$ and M. Ouhssine ${ }^{1 *}$}

${ }^{1}$ Laboratory of Agro-Physiology, Biotechnologies, Environment and Quality, Department of Biology, Faculty of Sciences, University Ibn Tofail, Kenitra, Morocco

${ }^{2}$ Laboratory of separation processes, Faculty of Science, University Ibn Tofail PO Box 242, Kenitra, Morocco

${ }^{3}$ Laboratory of Applied Chemistry and Environment, ENSA, University Ibn Zohr, PO Box 1136, Agadir, Morocco

${ }^{4}$ Laboratory of Electrical Engineering and Energy System, Faculty of Science, University Ibn Tofail, Kenitra, Morocco

*E-mail: ouhssineunivit@gmail.com

\begin{abstract}
The efficiency of Thymus satureioides essential oil (EO) as inhibitor of mild steel corrosion in hydrochloric acid $1.0 \mathrm{M}$ has been studied using polarization curves, electrochemical impedance spectroscopy (EIS) and weight loss measurements. The chemical composition of essential oil was characterized by 29 components, which accounted for $99.24 \%$ of the total oil. The major constituents were carvacrol $(29.65 \%)$, followed by borneol $(19.04 \%)$, linalool $(11.79 \%), p$-cymene $(8.53 \%)$, camphene $(7.01 \%), \gamma$-terpinene $(6.10 \%), \alpha$-pinene $(4.55 \%)$ and caryophyllene $(2.39 \%)$. The maximum inhibition efficiency (IE) $(90 \%)$ was observed at the optimum concentration of $1.5 \mathrm{~g} / \mathrm{L}$. The electrochemical impedance spectroscopy data have shown that the formation of a protective film decrease the double layer capacitance and increases in the charge transfer resistance of mild steel. Increasing temperature reduces surface covered by the inhibitor, which results in a decrease of percentage inhibition efficiency from $89 \%$ to $76 \%$. Polarization curves indicated that this EO can be classified as a mixed inhibitor in acidic medium with a predominant anodic inhibition. The value of enthalpy change is positive, which indicated endothermic adsorption process. The inhibition efficiencies calculated by weight loss exhibit a trend parallel to that of polarization and electrochemical impedance spectra measurements. We can conclude that essential oil extracted from T. Satureioides may be suggested as a green inhibitor against corrosion under acidic environment.
\end{abstract}

Keywords: Thymus satureioides, essential oil, mild steel, corrosion inhibition.

Received: December 11, 2018. Published: April 11, 2019

doi: $\underline{10.17675 / 2305-6894-2019-8-2-11}$ 


\section{Introduction}

The use of mild steel is foremost in several industries such as oil and gas and energy generating, possibly due to its superb mechanical properties and comparatively cheaper cost $[1,2]$. However, this steel is highly corrodible when exposed to acid solutions, causing severely financial and industrial losses. These acids have an important role in the industry. For instance, essential processes like pickling, descaling and oil well acidizing employ acids such as hydrochloric $(\mathrm{HCl})$ and sulfuric $\left(\mathrm{H}_{2} \mathrm{SO}_{4}\right)$ acid solutions [3-5]. There are several methods to protect or prevent metal surface from corrosion, such as barrier protection [6], galvanization [7], cathodic protection [8], etc. However, these techniques are often unsuitable when the metal is exposed to a corrosive medium for a long time. Therefore, the use of corrosion inhibitors is one of the most common methods applied for protecting metal or alloy surfaces in acidic environment [9-14].

In the last decades, environment protection became a major concern. In the field of science, researches turned to anything biodegradable and respectful of the environment. In corrosion inhibition field, research has been devoted on corrosion prevention by green inhibitors namely also ecofriendly inhibitors that show good inhibitory effect with low risk of environmental and low cost $[1,2,10,15-17]$. The Thymus species are widely distributed in various regions in Morocco [18]. The percentage of endemism is 46.6\%, representing seven species [19]. Among these species, Thymus satureioides is an endemic plant of Morocco [20], known under the following vernacular names, in Tamazight "Azukni", "Tazuknit", in Arabic "Zaitra" [20].

The purpose of this study is the evaluation of the effectiveness of the flowering tops essential oil of Thymus satureioides on steel corrosion in 1.0 M hydrochloric acid, using potentiodynamic polarization curves (PDP), electrochemical impedance spectroscopy (EIS) and gravimetric measurements.

\section{Experimental procedure}

\subsection{Plant materiel and volatile oil isolation}

Flowering tops of Thymus satureioides were harvested in Taltemssen region (south region of Agadir, Morocco) during the month of May, and then they are air-dried in the shade at ambient temperature for a week. The volatile oil was isolated by hydrodistillation with Clevenger device, according to European pharmacopoeia procedure [21]. The oil obtained was dried with anhydrous sodium sulfate $\left(\mathrm{Na}_{2} \mathrm{SO}_{4}\right)$ and then stored in brown bottles at 4 degrees centigrade to avoid its evaporation and decomposition.

\subsection{Components identification}

The device used is of type: Perkin Elmer Auto System XL, equipped with a flame ionization detector (FID). $0.2 \mu \mathrm{l}$ of EO are injected using a micro-syringe. Nitrogen $\left(\mathrm{N}_{2}\right)$ was used as a vector gas at a flow rate of $1 \mathrm{~mL} / \mathrm{min}$. The column used is a capillary 
column of Elite type $(60 \mathrm{~m} \times 0.320 \mathrm{~mm})$, the film thicknesses is $1.0 \mu \mathrm{m}$, flow rate of hydrogen $\left(\mathrm{H}_{2}\right) 35 \mathrm{~mL} / \mathrm{min}$, synthetic air flow $350 \mathrm{~mL} / \mathrm{min}$, injection temperature $235^{\circ} \mathrm{C}$, detection temperature: $240^{\circ} \mathrm{C}$. The programming of the temperature of the column is as follows: the initial injection temperature is $50^{\circ} \mathrm{C}$ for $5 \mathrm{~min}$ then rises in increments of $4^{\circ} \mathrm{C} / \mathrm{min}$ at $230^{\circ} \mathrm{C}$ for $5 \mathrm{~min}$.

\subsection{Corrosion study}

\subsubsection{Steel samples}

Mild steel $(2.5 \times 2.0 \times 0.2 \mathrm{~cm})$ was used as substrate whose chemical composition is $0.370 \% \mathrm{C}, 0.011 \% \mathrm{Ti}, 0.077 \% \mathrm{Cr}, 0.680 \% \mathrm{Mn}, 0.016 \% \mathrm{~S}, 0.059 \%$ of $\mathrm{Ni}, 0.009 \%$ of Co, $0.230 \% \mathrm{Si}, 0.160 \%$ of $\mathrm{Cu}$ and the remainder iron $(\mathrm{Fe})$. The steel surface was mechanically polished using abrasive paper up to 1600 grade. The impurity on the surface was washed with bidistilled water and acetone.

\subsubsection{Solution preparation}

The aggressive solution is hydrochloric acid solution $(1.0 \mathrm{M} \mathrm{HCl})$ prepared from concentrated commercial acid at $37 \%$ and double distilled water. The concentrations of EO used in this study were varied from 0.05 to $1.5 \mathrm{~g} / \mathrm{L}$.

\subsubsection{Gravimetric measurements}

In the gravimetric experiment, the metal coupons were immersed 6 hours in $1.0 \mathrm{M}$ of hydrochloric solution containing different concentrations of the inhibitor. The metal specimens were immersed in the acidic solution with the help of glass hooks. The specimen weights were noted before immersion. After 6 hours of immersion to $\mathrm{HCl}$ medium, the steel specimens were removed, rinsed with bidistilled water, cleaning in acetone, dried at ambient temperature and then weighted. All the values are the means of three measurements. The solution volume is $100 \mathrm{~mL}$.

\subsubsection{Electrochemical study}

Impedance measurements analyzing are carried out with a mounting comprising a Tacussel potentiostat, type Radiometer PGZ 100, controlled by Voltamaster4 software. Threeelectrode consisting of saturated calomel (SCE) as reference electrode, platinum as an auxiliary electrode, and mild steel as working electrode were used for electrochemical test. The specimen (working electrode) was immersed in the experimental solution for 30 minutes until an open circuit potential $\left(E_{\text {ocp }}\right)$ was obtained. Electrochemical study was performed in air-saturated $1.0 \mathrm{M} \mathrm{HCl}$ solution at $303 \mathrm{~K}$.

Intensity-potential curves or polarization curves of the metal-electrolyte interface were recorded from -800 to $-200 \mathrm{mV} / \mathrm{SCE}$ at constant temperature $(303 \mathrm{~K})$ with a sweep of $1 \mathrm{mV} \cdot \mathrm{s}^{-1}$. A thermostated bath was used to maintain the solution temperature at desired temperature. Electrochemical impedance spectroscopic measurements were conducted at 
OCP in the frequency range of $10^{-1} \mathrm{~Hz}$ to $10^{5} \mathrm{~Hz}$ and peak-to-peak amplitude of $5 \mathrm{mV}$ was measured with a data density of 10 points per decade.

\section{Results and discussion}

\subsection{Identification of compounds}

The oil was analyzed by gas chromatography. In total, 29 components were identified, representing $99.33 \%$ of the total oil (Table 1). The oxygenated and hydrocarbon monoterpenes contributed $65.39 \%$ and $30.47 \%$ in oil sample, followed by sesquiterpenes hydrocarbons and oxygenated sesquiterpenes $(3.13 \%$ and $0.34 \%)$.

The major components of the essential oil were carvacrol $(29.65 \%)$, followed by borneol (19.04\%), linalool (11.79\%), p-cymene (8.53\%), camphene $(7.01 \%), \gamma$-terpinene (6.10\%), $\alpha$-pinene $(4.55 \%)$ and caryophyllene $(2.39 \%)$. This composition is close to that given by A. Kasrati et al. [22] of the essential oil extracted from aerial parts of Thymus satureioides in the Ourika region, which it consists of $26.5 \%$, carvacrol, $20.1 \%$ of borneol, $8 \%$ of camphene, $5.4 \%$ of caryophyllene and $3.8 \%$ of linalool. Both samples contain carvacrol and borneol as major components. Another study was carried out in the Ifrane region (Middle Atlas) on the essential oil of $T$. satureioides, which represents as major components $27.59 \%$ of cymene and $14.09 \%$ of thymol [23], this last component was not identified in essential oil of our plant.

This difference in composition is probably due to various conditions including environment, genotype, geographical origin, harvest period, location of drying, temperature, drying time, parasites and extraction method [24, 25].

Table 1. Chemical composition of Thymus satureioides essential oil.

\begin{tabular}{ccc}
\hline Constituents & Kovat's Index & EOFT (\%) \\
\hline & Monoterpenes hydrocarbons & \\
\hline Tricyclene & 928 & 0.28 \\
$\alpha$-Pinene & 950 & 4.55 \\
Camphene & 960 & 7.01 \\
Sabinene & 976 & 1.07 \\
$\beta$-Pinene & 980 & 1.35 \\
3-Carene & 1016 & 1.58 \\
$p$-Cymene & 1026 & 8.53 \\
$\gamma$-Terpinene & 1062 & 6.10 \\
& Monoterpenes oxygenated & \\
\hline a-Thujene & 938 & 1.41 \\
3-Octanol & 994 & 0.21 \\
1,8-Cineol & 1033 & 0.78 \\
\hline
\end{tabular}




\begin{tabular}{|c|c|c|}
\hline Constituents & Kovat's Index & EOFT (\%) \\
\hline Linalol & 1098 & 11.79 \\
\hline Borneol & 1166 & 19.04 \\
\hline Terpineol-4 & 1178 & 1.81 \\
\hline Cis-Dihydrocarvone & 1194 & 0.16 \\
\hline Bornyl acetate & 1286 & 0.45 \\
\hline Carvacrol & 1299 & 29.65 \\
\hline \multicolumn{3}{|c|}{ Sesquiterpenes hydrocarbons } \\
\hline$\alpha$-Copaene & 1377 & 0.06 \\
\hline$\alpha$-Guaience & 1440 & 0.05 \\
\hline Caryophyllene & 1419 & 2.39 \\
\hline Aromadendrene & 1440 & 0.05 \\
\hline$\alpha$-Patchoulene & 1456 & 0.11 \\
\hline Germacrene D & 1480 & 0.03 \\
\hline$\alpha$-Muurolene & 1499 & 0.15 \\
\hline$\gamma$-cadinene & 1513 & 0.07 \\
\hline$\delta$-cadinene & 1524 & 0.22 \\
\hline \multicolumn{3}{|c|}{ Sesquiterpenes oxygenated } \\
\hline Spathulenol & 1576 & 0.07 \\
\hline Caryophyllene oxide & 1581 & 0.13 \\
\hline Cadinol & 1653 & 0.14 \\
\hline Monoterpenes oxygenated & & 65.39 \\
\hline Monoterpenes hydrocarbons & & 30.47 \\
\hline Sesquiterpenes hydrocarbons & & 3.13 \\
\hline Sesquiterpenes oxygenated & & 0.34 \\
\hline Total identified compounds & & 99.33 \\
\hline
\end{tabular}

\subsection{Weight loss test}

\subsubsection{Inhibitor concentration effect}

The samples are immersed in hydrochloric solution without and with addition of EO at specified inhibitor concentrations $(0.05,0.1,1.0$ and $1.5 \mathrm{~g} / \mathrm{L})$. The rate of steel corrosion $(C R)$ and inhibitor efficiency (IE \%) were determined by using the equations 1 and 2 [26], respectively:

$$
\begin{gathered}
W=W_{b}-W_{a} / A t \\
I E(\%)=\left(C R-C R_{\mathrm{inh}} / C R\right) \times 100
\end{gathered}
$$


Where $W_{\mathrm{b}}$ and $W_{\mathrm{a}}$ are the mass losses before and after immersion in acidic solution; $C R$, $C R_{\text {inh }}$ are the rate of steel corrosion in the absence and presence of EO, respectively. $A$ is the surface area of steel specimen $\left(\mathrm{cm}^{2}\right)$ and $t(\mathrm{~h})$ is the immersion time.

It can be seen from Table 2 and Figure 1 that the EO acted as a suitable inhibitor of steel corrosion under the investigated conditions. The rate of steel corrosion decreases when the concentration of inhibitor increases, while the values of $I E(\%)$ increased with a corresponding increase in the inhibitor concentration. At $1.5 \mathrm{~g} / \mathrm{L}$ concentration of oil, the inhibition percentage achieved $90 \%$.

Table 2. Results of weight loss method for the corrosion of mild steel in hydrochloric acid at specified concentrations of $\mathrm{EO}$ at $303 \mathrm{~K}$.

\begin{tabular}{ccccc}
\hline Inhibitor & Conc. & Corrosion rate $\left(\mathbf{m g} / \mathbf{c m}^{\mathbf{2}} \mathbf{h}\right)$ & Inhibition efficiency $(\boldsymbol{\%})$ & Surface coverage $(\boldsymbol{\theta})$ \\
\hline Blank & - & 1.135 & - & - \\
\hline \multirow{2}{*}{ EO } & 0.05 & 0.329 & 71 & 0.71 \\
& 0.1 & 0.272 & 76 & 0.76 \\
& 1.0 & 0.147 & 87 & 0.87 \\
& 1.5 & 0.113 & 90 & 0.90 \\
\hline
\end{tabular}

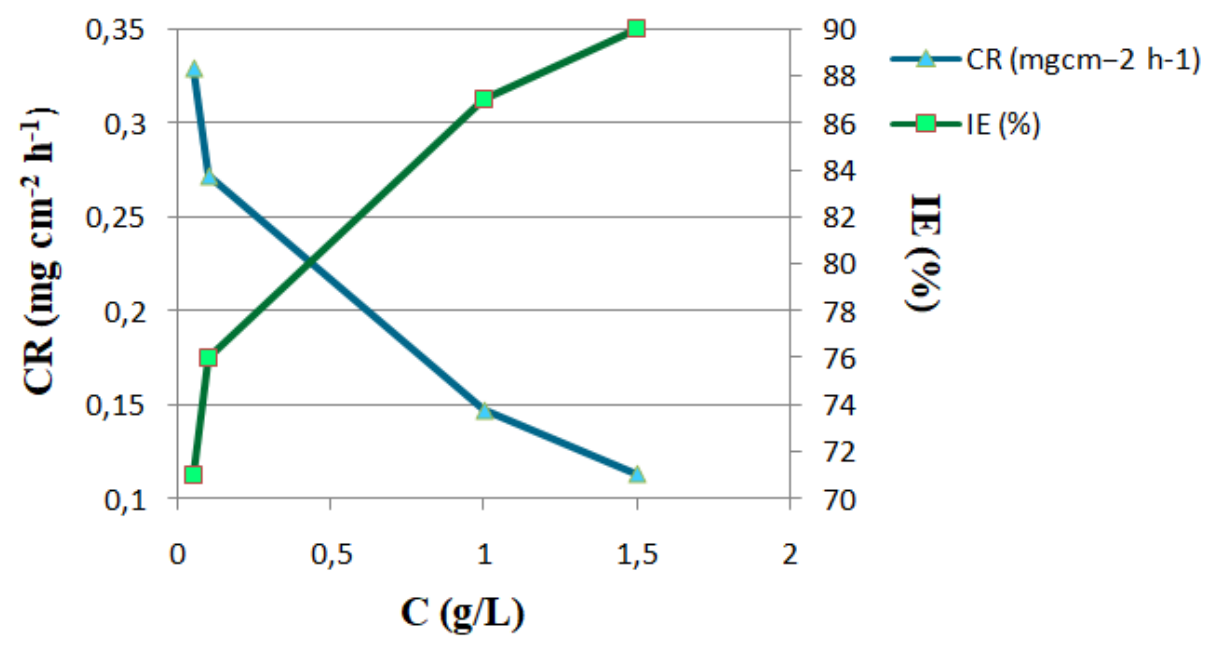

Figure 1. Steel corrosion rate and inhibitor efficiency in $\mathrm{HCl}$ medium at varying concentrations of essential oil.

\subsubsection{Temperature effect}

The temperature is one of the factors that can alter the inhibitors and substrates behavior in a corrosive environment [27]. The higher temperatures promote desorption of inhibitor or its decomposition thus causing a weakening of the corrosion resistance of steel [28]. Weight 
loss tests were conducted at different temperatures from 303 to $333 \mathrm{~K}$ in order to study the temperature effect on adsorption/desorption processes. Increasing temperature reduces surface covered by the adsorbed inhibitor, which results in a decrease of percentage inhibition efficiency from $89 \%$ to $76 \%$ (Table 3, Figure 2). This result can be explained by desorption process of inhibitor at high temperature, suggesting physisorption mechanism.

Table 3. Temperature effect on steel corrosion in the absence and presence of $1.5 \mathrm{~g} / \mathrm{L}$ essential oil.

\begin{tabular}{ccccc}
\hline Inhibitor & Temperature (K) & $\begin{array}{c}\mathbf{C R} \\
\left(\mathbf{m g} / \mathbf{c m}^{\mathbf{2}} \mathbf{h}\right)\end{array}$ & $\boldsymbol{I E} \mathbf{( \% )}$ & Surface coverage $(\boldsymbol{\theta})$ \\
\hline \multirow{3}{*}{ Blank } & 303 & 1.135 & - & - \\
& 313 & 2.466 & - & - \\
& 323 & 5.032 & - & - \\
& 333 & 10.029 & - & - \\
\hline \multirow{3}{*}{$1.5 \mathrm{~g} / \mathrm{L}$ of EO } & 303 & 0.124 & 89 & 0.89 \\
& 313 & 0.334 & 86 & 0.86 \\
& 323 & 0.965 & 80 & 0.80 \\
& 333 & 2.318 & 76 & 0.76 \\
\hline
\end{tabular}

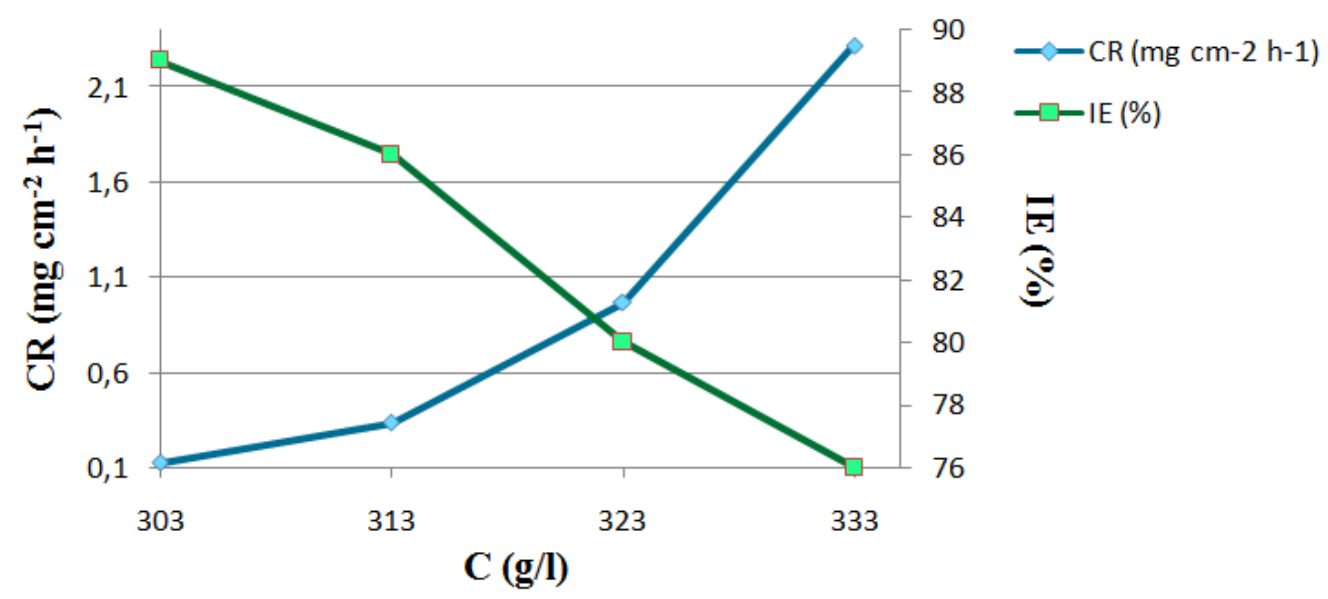

Figure 2. Variation of steel corrosion rate and protection efficiency as a function of temperature.

The Arrhenius plot shown in Figure 3 and the transition state plot (Figure 4) allowed to deduct the activation energy values in uninhibited and inhibited solution, the results are listed in Table 4. The temperature dependency of current density can be best represented by the Arrhenius and transition state equations [29, 30]:

$$
C R=k \exp \left(\frac{-E_{a}^{*}}{R T}\right)
$$




$$
C R=\frac{R T}{\mathrm{~N} \hbar} \exp \left(\frac{\Delta S_{a}^{*}}{R}\right) \exp \left(-\frac{\Delta H_{a}^{*}}{R T}\right)
$$

Where, $\hbar$ is Plank's constant, $E_{\mathrm{a}}^{*}$ is the apparent activation energy, $N$ is Avogadro's number, $\Delta S_{\mathrm{a}}^{*}$ is the entropy of activation, $\Delta H_{\mathrm{a}}^{*}$ is the enthalpy of activation, $R$ is the gas constant, $T$ is the temperature, $k$ is the Arrhenius pre-exponential factor. These two graphs give a straight line.

In order to understand the nature of adsorption process, the thermodynamic parameters such as activation energy $\left(E_{\mathrm{a}}\right)$ standard enthalpy $(\Delta H)$, and entropy $(\Delta S)$ were calculated. It is clear from Table 4 that $E_{\mathrm{a}}$ value for the corrosion process is higher compared to that obtained in the uninhibited solution. The increased value of the $\left(E_{\mathrm{a}}^{*}\right)$ in the presence of EO could presumably due to the generation of energy barrier for the corrosion reaction in the presence of inhibitor. The same phenomenon was observed during the work of other researchers [31,32]. The standard enthalpy change $(\Delta H)$ can provide valuable information about adsorption process type. Positive value of enthalpy change indicates that adsorption process is endothermic [33]. The reduction in inhibition efficiency $(I E \%)$ with increase in temperature and higher $E_{\mathrm{a}}$ value in the inhibitor's presence compared to the blank suggest a physical adsorption mechanism. The effect corresponding to an increase in protection efficiency and the lower value of $E_{\mathrm{a}}$ in inhibited solution to be indicative of chemisorption. In this work, the higher value of activation energy (activated adsorption) shows that the adsorbed inhibitor has created a physical barrier to the charge transfer, leading to reduction in corrosion rate. It is well noticed that the entropy value increases from -98.8 to $-16.86 \mathrm{~J} \cdot \mathrm{mol}^{-1} \cdot \mathrm{K}^{-1}$. This result can be explained by replacement of water molecule during the adsorption process of essential oil on the substrate surface [34].

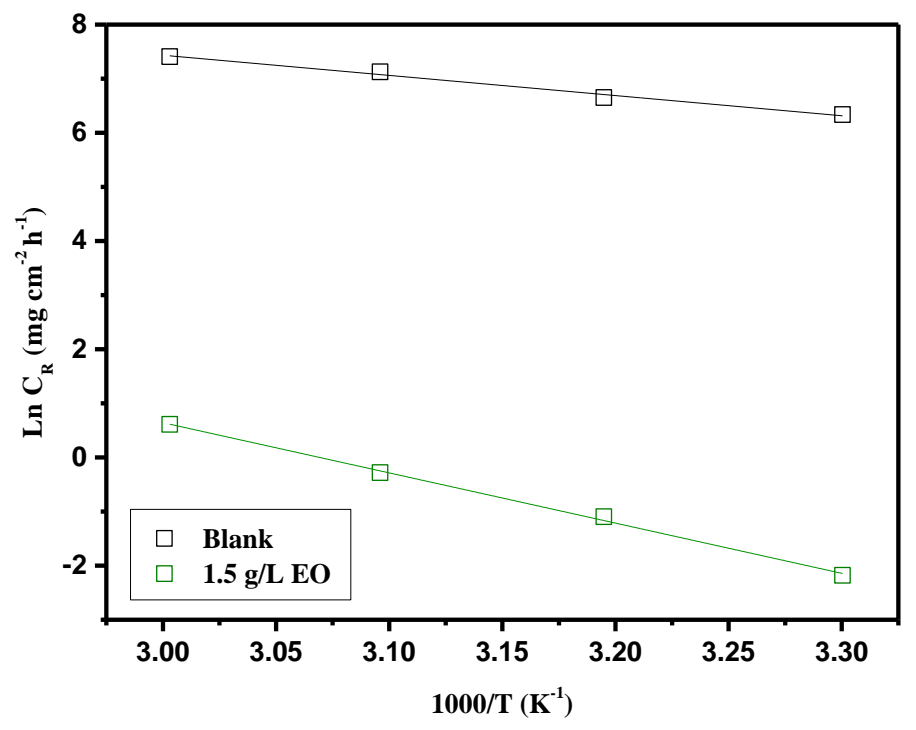

Figure 3. Arrhenius plots of mild steel in absence and presence of $1.5 \mathrm{~g} / \mathrm{l}$ inhibitor. 


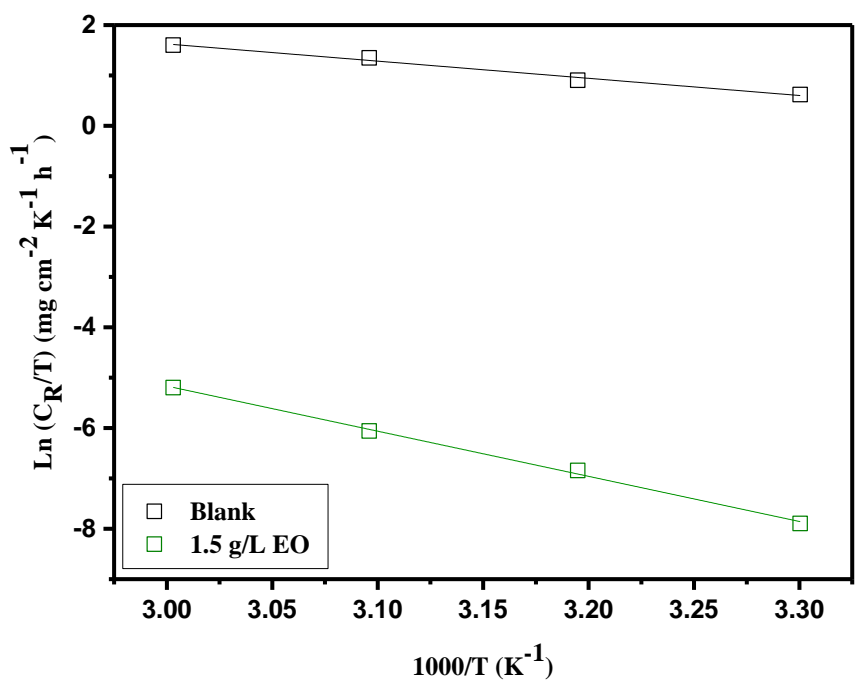

Figure4. Transition state plots $(\mathrm{HCl}$ and $\mathrm{HCl}+1.5 \mathrm{~g} / \mathrm{L} \mathrm{EO})$.

Table 4. Activation parameters for the essential oil adsorption onto the steel surface.

\begin{tabular}{ccccc}
\hline Inhibitor & $\begin{array}{c}\boldsymbol{E}_{\boldsymbol{a}} \\
\left(\mathbf{k J} \cdot \mathbf{m o l}^{-\mathbf{1}}\right)\end{array}$ & $\begin{array}{c}\Delta \boldsymbol{H}_{\text {ads }} \\
\left(\mathbf{k J} \cdot \mathbf{m o l}^{\mathbf{- 1}}\right)\end{array}$ & $\begin{array}{c}\Delta \boldsymbol{S}_{\text {ads }} \\
(\mathbf{J} / \mathbf{m o l} \cdot \mathbf{K})\end{array}$ & $\boldsymbol{E}_{\mathbf{a}}-\Delta \boldsymbol{H}_{\mathbf{a}}$ \\
\hline Blank & 31.00 & 28.35 & -98.8 & 2.65 \\
\hline $1.5 \mathrm{~g} / \mathrm{l}$ of EO & 77.16 & 74.52 & -16.86 & 2.64 \\
\hline
\end{tabular}

\subsection{Polarization curve method}

Figure 5 shows the anodic and cathodic polarization curves of steel in hydrochloric medium in the presence and absence of inhibitor. The polarization parameters such corrosion current density $\left(i_{\text {corr }}\right)$, corrosion potential $\left(E_{\text {corr }}\right)$, and inhibition efficiency $(I E \%)$ for different concentrations of inhibitor are presented in Table 5. The protection efficiency (\%) was determined by applying the equation below (5):

$$
\operatorname{IE}(\%)=\frac{i_{\text {corr }}^{0}-i_{\text {corr }}}{i_{\text {corr }}^{0}} \times 100
$$

Where $i_{\text {corr }}$ and $i_{\text {corr }}^{0}$ are corrosion current densities in the uninhibited and inhibited acid solutions respectively. 


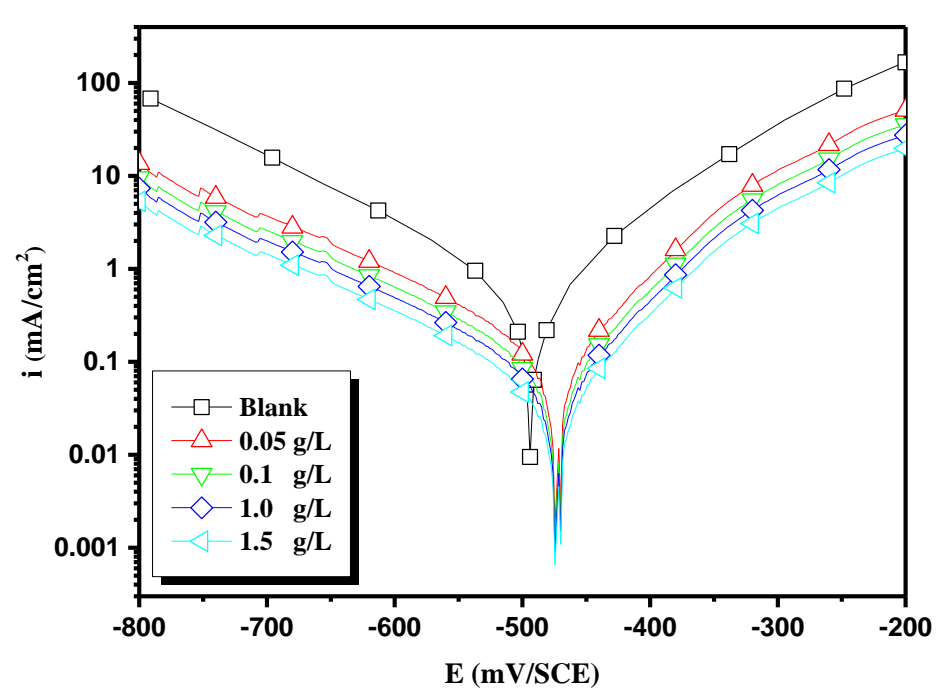

Figure 5. Polarization curves of mild steel in hydrochloric solution for various inhibitor concentrations at $303 \mathrm{~K}$.

Figure 5 shows that the effect of the solution containing inhibitor on the steel presents an anodic and cathodic behavior. The addition of the essential oil in a corrosive medium induces a decrease of the two partial currents cathodic and anodic, reducing of mild steel dissolution and hydrogen evolution reaction in acid solution. The anodic reaction was more effectively than the cathodic reaction of steel. This result indicates that essential oil of the studied plant is a mixed inhibitor with a less predominant anodic effect. The data showed in Table 5 indicate that the inhibitor decreases the corrosion current densities $\left(i_{\text {corr }}\right)$, meaning that the steel corrosion rate is reduced. After the addition of the inhibitor, the current ( $\mathrm{i}_{\text {corr }}$ decreases from 153 to $59 \mu \mathrm{A} / \mathrm{cm}^{2}$, but the corrosion potential $\left(E_{\text {corr }}\right)$ remains almost the same. The protection efficiency increased with the inhibitor concentrations to reach $89 \%$ at $1.5 \mathrm{~g} / \mathrm{L}$. The corrosion protection efficiencies obtained from potentiodynamic polarization curves is in good agreement with results obtained from the gravimetric tests.

Table 5. Polarization measurements of steel in acid medium with specified concentrations of oil at constant temperature (303 K).

\begin{tabular}{ccccc}
\hline Inhibitor & $\begin{array}{c}\text { Conc. } \\
(\mathbf{g} / \mathbf{l})\end{array}$ & $\begin{array}{c}-\boldsymbol{E}_{\text {corr }} \\
(\mathbf{m V} / \mathbf{S C E})\end{array}$ & $\begin{array}{c}\boldsymbol{i}_{\text {corr }} \\
\left(\boldsymbol{\mu} \mathbf{A} / \mathbf{c m}^{2}\right)\end{array}$ & $\boldsymbol{I E}(\boldsymbol{\%})$ \\
\hline Blank & - & 496.0 & 564.0 & - \\
\hline \multirow{3}{*}{ EO } & 0.05 & 473 & 153 & 73 \\
& 0.1 & 474 & 107 & 81 \\
& 1.0 & 477 & 83 & 85 \\
& 1.5 & 475 & 59 & 89 \\
\hline
\end{tabular}




\subsection{Impedance measurements study}

The addition of the EO as inhibitor on the mild steel corrosion in acid solution was studied by electrochemical impedance spectroscopy measurements at $303 \mathrm{~K}$ after 30 minutes of immersion (Figure 6). The results obtained from the Nyquist diagrams are collected in Table 6.

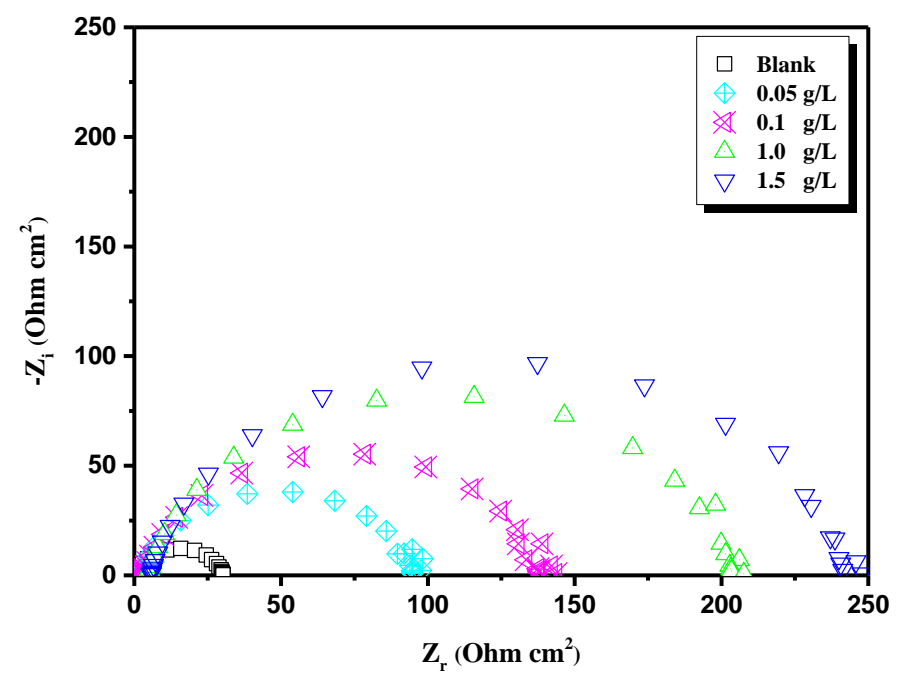

Figure 6. Effect of essential oil concentrations on the Nyquist diagram of mild steel in $\mathrm{HCl}$ at constant temperature $(303 \mathrm{~K})$.

Table 6: EIS parameters for steel corrosion in HCL in the absence and presence of EO.

\begin{tabular}{ccccccc}
\hline Inhibitor & $\begin{array}{c}\text { Conc. } \\
(\mathbf{g} / \mathbf{L})\end{array}$ & $\begin{array}{c}\boldsymbol{R}_{\mathbf{t}} \\
\left(\mathbf{\Omega} \cdot \mathbf{c m}^{2}\right)\end{array}$ & $\boldsymbol{n}$ & $\begin{array}{c}\boldsymbol{Q} \mathbf{~ 1 0}^{-4} \\
\left(\mathbf{s}^{\mathbf{4}} \mathbf{\Omega} \cdot \mathbf{c m}^{\mathbf{2}}\right)\end{array}$ & $\begin{array}{c}\boldsymbol{C}_{\mathbf{d}} \\
\left(\boldsymbol{\mu F} \cdot \mathbf{c m}^{-\mathbf{2}}\right)\end{array}$ & $\boldsymbol{I E}(\boldsymbol{\%})$ \\
\hline Blank & - & 29.35 & 0.91 & 1.7610 & 91.63 & - \\
\hline \multirow{3}{*}{ EO } & 0.05 & 93 & 0.81 & 1.1543 & 40 & 68 \\
& 0.1 & 135 & 0.81 & 0.8911 & 31 & 78 \\
& 1.0 & 196 & 0.86 & 0.4449 & 20 & 85 \\
& 1.5 & 236 & 0.86 & 0.3689 & 17 & 87 \\
\hline
\end{tabular}

The Nyquist impedance diagram in Figure 7 exhibited a depressed semi-circle indicating a double layer capacitance, this depression (no perfect semi-circle) is may be the result of surface heterogeneous, which results from adsorption of the inhibitor, distribution of the active sites and surface roughness [35, 36], or formation of porous layers [37, 38]. The value of $n$ can be used as a measure of the roughness on the steel surface [39, 40]. We can observe the increase of depressed semi-circle diameter with an increase in inhibitor concentration results from the adsorption of the essential oil on mild steel surface [41] and 
formation of a protective layer. The structural model shown in figure 7 was used to analyze the EIS tests. This circuit consists of a constant phase element $(Q)$, used to account for the previously described inhomogeneities, the electrolyte resistance $\left(R_{\mathrm{s}}\right)$ and the resistance $\left(R_{\mathrm{ct}}\right)$. It is by a constant phase element (CPE) that one reports the inhomogeneities of surface by the intermediary of the coefficient $n$. Such an element is described by:

$$
Z_{\mathrm{CPE}}=\frac{1}{Q(j \omega)^{n}}
$$

Where $Q$ is the CPE constant (in $\Omega^{-1} \cdot \mathrm{S}^{n} \cdot \mathrm{cm}^{-2}$ ), $\omega$ is the angular frequency (in $\mathrm{rad} \cdot \mathrm{s}^{-1}$ ), $j^{2}=-1$ is the imaginary number and $n$ is a CPE exponent.

Hirschorn et al recently published that the effective capacity, $C_{\mathrm{dl}(\mathrm{eff})}$, can be estimated using the following mathematical formula from the CPE [42]:

$$
C_{d l(e f f)}=\sqrt[n]{Q \times R_{c t}^{1-n}}
$$

Where $Q$ is CPE constant and $\mathrm{n}$ is CPE exponent. The value of $n$ represents the deviation from the ideal behavior and it lies between 0 and 1 .

The calculated parameters are collected in Table 6 . The percentage protection efficiency is determined by the equation (8):

$$
\operatorname{IE}(\%)=R_{t}-R_{t}^{0} / R_{t} \times 100
$$

Where, $R_{t}^{0}$ and $R_{t}$ were the polarization resistance inclusive and exclusive of inhibitor, respectively.

It is apparent from Table 6 that the impedance of the inhibited system amplified with the inhibitor and the $C_{d}$ values decreased with inhibitor. This decrease in $C_{d}$ results from a decrease in local dielectric constant and/or an increase in the thickness of the double layer, suggested that EO molecules inhibit the mild steel corrosion by adsorption at the metal/acid interface [10].The impedance study confirms the inhibiting characters of the investigated inhibitor obtained with potentiostatic polarization and gravimetric methods. These observations show that the EO molecules are adsorbed on the mild steel surface. Thus, the investigated inhibitor can be used effectively to protect mild steel in acidic mediums.

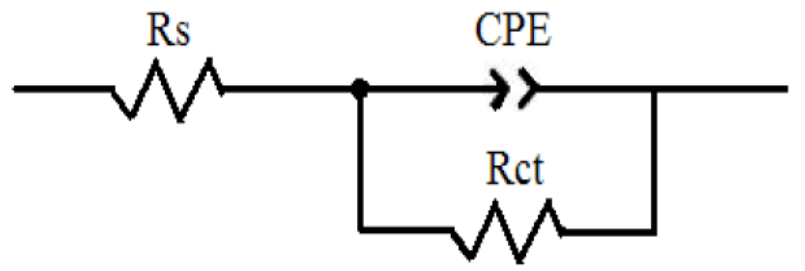

Figure 7. Equivalent electrical circuit of the electrochemical impedance spectra. CPE: constant phase element, $R_{s}$ : electrolyte resistance, $R_{c t}$ : charge transfer resistance. 


\section{Conclusion}

We can conclude from this study:

1. The major constituents of essential oil were carvacrol $(29.65 \%)$, followed by borneol (19.04\%), linalool (11.79\%), $p$-cymene $(8.53 \%)$, camphene $(7.01 \%), \gamma$-terpinene $(6.10 \%), \alpha$-pinene $(4.55 \%)$ and caryophyllene $(2.39 \%)$.

2. Good effectiveness of Thymus satureioides essential oil on steel corrosion in hydrochloric medium. The percentage protection efficiency achieved $89 \%$ at inhibitor concentration $1.5 \mathrm{~g} / \mathrm{L}$.

3. Essential oil is a mixed inhibitor with a predominant anodic inhibition.

4. The value of enthalpy is positive, which indicated endothermic adsorption process.

5. The inhibition efficiencies calculated by weight loss exhibit a trend parallel to that of polarization and electrochemical impedance spectra measurements.

\section{Acknowledgements}

A. Boukhraz is grateful to Dr. Hassane Lgaz, Konkuk University, South Korea for the support of this research.

\section{References}

1. V. Vorobyova, O. Chygyrynets, M. Skiba, T. Zhuk, I. Kurmakova and O. Bondar, Int. J. Corros. Scale Inhib., 2018, 7, no. 2, 185-202. doi: 10.17675/2305-6894-2018-7-2-6

2. A. Peter and S. Sharma, Int. J. Corros. Scale Inhib., 2017, 6, no. 2, 112-131. doi: 10.17675/2305-6894-2017-6-2-2

3. M. Messali, M. Larouj, H. Lgaz, N. Rezki, F.F. Al-Blewi, M.R. Aouad, A. Chaouiki, R. Salghi and I.-M. Chung, J. Mol. Struct., 2018, 1168, 39-48. doi: 10.1016/j.molstruc.2018.05.018

4. H. Lgaz, R. Salghi, K. Subrahmanya Bhat, A. Chaouiki, Shubhalaxmi and S. Jodeh, J. Mol. Liq., 2017, 244, 154-168. doi: 10.1016/j.molliq.2017.08.121

5. N. Saini, R. Kumar, H. Lgaz, R. Salghi, I.-M. Chung, S. Kumar and S. Lata, J. Mol. Liq., 2018, 269, 371-380. doi: 10.1016/j.molliq.2018.08.070

6. E. Akbarinezhad, M. Ebrahimi, F. Sharif, M.M. Attar and H.R. Faridi, Prog. Org. Coat., 2011, 70, 39.

7. S. Beyer, V. Dunkel, U. Hasselmann, R. Landgrebe and H. Speckhardt, Materialwiss. Werkstofftech., 1994, 25, 459.

8. M. Barbalat, L. Lanarde, D. Caron, M. Meyer, J. Vittonato, F. Castillon, S. Fontaine and P. Refait, Corros. Sci., 2012, 55, 246.

9. R. Aslam, M. Mobin, J. Aslam, H. Lgaz, Sci. Rep., 2018, 8, Article number: 3690. doi: 10.1038/s41598-018-21175-6

10. A.S. Fouda, S.A. Abd El-Maksoud, M.S. Zoromba and A.R. Ibrahim, Int. J. Corros. Scale Inhib., 2017, 6, no. 4, 428-448. doi: 10.17675/2305-6894-2017-6-4-4 
11. P. Dohare, D. Chauhana and M. Quraishic, Int. J. Corros. Scale Inhib., 2018, 7, no. 1, 25-37. doi: 10.17675/2305-6894-2018-7-1-3

12. A. Berezhnaya, G.A. Shayea and V. Chernyavina, Int. J. Corros. Scale Inhib., 2017, 6, no. 4, 372-383. doi: 10.17675/2305-6894-2017-6-4-2

13. R.S. Hameed, A. El-Zomrawy, M. Abdallah, E. Rehim, S. Abed, H. AlShafey and S.N. Edin, Int. J. Corros. Scale Inhib., 2017, 6, no. 2, 196-208. doi: 10.17675/2305$\underline{\text { 6894-2017-6-2-8 }}$

14. R. Hameed and A. Shamroukh, Int. J. Corros. Scale Inhib., 2017, 6, no. 3, 333-348. 10.17675/2305-6894-2017-6-3-8

15. D.I. Njoku, Y. Li, H. Lgaz and E.E. Oguzie, J. Mol. Liq., 2018, 249, 371-388. doi: 10.1016/j.molliq.2017.11.051

16. R. Kumar, S. Chahal, S. Kumar, S. Lata, H. Lgaz, R. Salghi and S. Jodeh, J. Mol. Liq., 2017, 243, 439-450. doi: 10.1016/j.molliq.2017.08.048

17. H. Lgaz, I.-M. Chung, R. Salghi, I.H. Ali, A. Chaouiki, Y. El Aoufir and M.I. Khan, Appl. Surf. Sci., 2019, 463, 647-658. doi: 10.1016/j.apsusc.2018.09.001

18. E. Jahandiez and R. Maire, Catalog of Moroccan Flora, Minerva, 1934, 653.

19. M. Fennane, M. Ibn Tattou, J. Mathez, A. Ouyahya and J. El Oualidi, Trav. Inst. Sci. Ser. Bot., 2007, no. 38. Scientific Institute, Rabat, Morocco, 477-482.

20. J. Bellakhdar, Traditional Moroccan pharmacopoeia. Ancient Arabic medicine and popular knowledge, Paris, Ibis Press, 1997, pp. 358-359.

21. European Pharmacopoeia 6.0, 2007, Vol. 1, Council of Europe, Strasbourg Cedex.

22. A. Kasrati, C. Alaoui Jamali, M. Fadli, K. Bekkouche, L. Hassani, H. Wohlmuth, D. Leach and A. Abbada, Ind. Crops Prod., 2014, 61, 338-344.

23. A.El Oualilalami, F.El Akhal, W. Ouedrhiri, C.F. Ouazzani, R. Guemmouh and H. Greche, Les technologies de laboratoire, 2013, 8, 27-33.

24. K.P. Svoboda and J.B. Hampson, Bioactivity of essential oils of selected temperate aromatic plants: antibacterial, antioxidant, antiinflammatory and other related pharmacological activities, Plant Biology Department, SAC Auchincruive, Ayr, Scotland, UK, KA6 5HW, 1999, pp. 1-17.

25. L. Gachkar, D. Yadegari, R.M. Bagher, M. Taghizadeh, A.S. Alipoor and I. Rasooli, Food Chem., 2007, 102, 898-904.

26. H. Zarrok, A. Zarrouk, B. Hammouti, R. Salghi, C. Jama and F. Bentiss, Corros. Sci., 2012, 64, 243.

27. P. Bommersbach, C. Alemany-Dumont, J.P. Millet and B. Normand, Electrochim. Acta, 2005, 51, no. 6, 1076-1084. doi: 10.1016/j.electacta.2005.06.001

28. F. Bentiss, M. Lebrini and M. Lagrenée, Corros. Sci., 2005, 47, no. 12, 2915-2931.

29. B. Xu, Y. Liu, X. Yin, W. Yang and Y. Chen, Corros. Sci., 2013, 74, 206-213.

30. B. Xu, W. Yang, Y. Liu, X. Yin, W. Gong and Y. Chen, Corros. Sci., 2014, 78, 260268.

31. M. Larouj, H. Lgaz, R. Salghi， S. Jodeh, M. Messali， M. Zougagh, H. Oudda and A. Chetouani, Moroccan J. Chem., 2016, 4, 567-583. 
32. H. Ouici, O. Benali, Y. Harek, L. Larabi, B. Hammouti and A. Guendouzi, Res. Chem. Intermed., 2013, 39, 2777-2793.

33. Y. Liu, J. Chem. Eng. Data, 2009, 54, 1981-1985.

34. M. Dahmani, A. El-Touhami, S.S. Al-Deyab, B. Hammouti and A. Bouyanzer, Int. J. Electrochem. Sci., 2010, 5, 1060.

35. W.R. Fawcett, Z. Kovacova, A. Motheo and C. Foss, J. Electroanal. Chem., 1992, 326, 91.

36. S.K. Shukla and M.A. Quraishi, Corros. Sci., 2009, 51, 1990.

37. A.A. Hermas, M.S. Morad and M.H. Wahdan, J. Appl. Electrochem., 2004, 34, 95.

38. A. Popova, S. Raicheva, E. Sokolova and M. Christov, Langmuir, 1996, 12, 1083.

39. Z.B. Stoynov, B.M. Grafov, B.S. Stoynova and V.V. Elkin, Elektrokhimicheskii Impedans (Electrochemical Impedance), Nauka, Moscow, 1991 (in Russian).

40. D.A. Lopez, S.N. Simison and S.R. de Sanchez, Electrochim. Acta, 2003, 48, 845.

41. M. Yadav, D. Behera and S. Kumar, Surf. Interface Anal., 2014, 46, 640-652.

42. C. Hsu and F. Mansfeld, Corrosion, 2001, 57, 747. 